OPEN ACCESS

Edited by:

Fred Stoddard,

University of Helsinki, Finland

Reviewed by:

Massimo Reverberi,

Sapienza University of Rome, Italy

Antonio Moretti,

National Research Council, Italy

${ }^{*}$ Correspondence:

Maciej Buśko

mabu@up.poznan.pl

Specialty section: This article was submitted to Crop Science and Horticulture, a section of the journal

Frontiers in Plant Science

Received: 04 March 2016 Accepted: 04 August 2016

Published: 22 August 2016

Citation:

Buśko M, Stuper K, Jeleń H, Góral T, Chmielewski J, Tyrakowska B and Perkowski J (2016) Comparison of Volatiles Profile and Contents of Trichothecenes Group B, Ergosterol, and ATP of Bread Wheat, Durum Wheat, and Triticale Grain Naturally

Contaminated by Mycobiota.

Front. Plant Sci. 7:1243.

doi: 10.3389/fpls.2016.01243

\section{Comparison of Volatiles Profile and Contents of Trichothecenes Group B, Ergosterol, and ATP of Bread Wheat, Durum Wheat, and Triticale Grain Naturally Contaminated by Mycobiota}

\author{
Maciej Buśko ${ }^{1 *}$, Kinga Stuper ${ }^{1}$, Henryk Jeleñ ${ }^{2}$, Tomasz Góral ${ }^{3}$, Jarosław Chmielewski ${ }^{4}$, \\ Bożena Tyrakowska ${ }^{4}$ and Juliusz Perkowski ${ }^{1}$ \\ ${ }^{1}$ Department of Chemistry, Poznań University of Life Sciences, Poznan, Poland, ${ }^{2}$ Department of Food Science and Nutrition, \\ Poznań University of Life Sciences, Poznan, Poland, ${ }^{3}$ Department of Plant Pathology, Plant Breeding and Acclimatization \\ Institute NRI, Radzików, Poland, ${ }^{4}$ Department of Instrumental Analysis, Poznań University of Economics, Poznan, Poland
}

In natural conditions cereals can be infested by pathogenic fungi. These can reduce the grain yield and quality by contamination with mycotoxins which are harmful for plants, animals, and humans. To date, performed studies of the compounds profile have allowed for the distinction of individual species of fungi. The aim of this study was to determine the profile of volatile compounds and trichothecenes of group B, ergosterol, adenosine triphosphate content carried out on a representative sample of 16 genotypes of related cereals: triticale, bread wheat, and durum wheat. Based on an analysis of volatile compounds by means of gas chromatography mass spectrometry and with the use of an electronic nose, volatile profiles for cereals were determined. Differentiation is presented at four levels through discriminant analysis, heatmaps, principal component analysis (PCA), and electronic nose maps. The statistical model was built by subsequent incorporation of chemical groups such as trichothecenes (GC/MS), fungal biomass indicators ergosterol (HPLC) and ATP (luminometric) and volatiles. The results of the discriminatory analyses showed that the volatile metabolites most markedly differentiated grain samples, among which were mainly: lilial, trichodiene, $p$-xylene. Electronic nose analysis made it possible to completely separate all the analyzed cereals based only on 100 ions from the $50-150 \mathrm{~m} / \mathrm{z}$ range. The research carried out using chemometric analysis indicated significant differences in the volatile metabolites present in the grain of bread wheat, durum wheat and triticale. The end result of the performed analyses was a complete discrimination of the examined cereals based on the metabolites present in their grain.

Keywords: volatile organic compounds, trichothecenes, ergosterol, ATP, bread wheat, durum wheat, triticale 


\section{INTRODUCTION}

Cereals are a staple food in human nutrition and are also the most important materials in farming for animal feeds (Condain, 1999). Several species of cereals are grown, among which wheat cultivation plays a crucial role. Despite genetic similarities, well known cultivated varieties of wheat differ from each other, viz.: durum wheat [Triticum turgidum $\mathrm{L}$. subsp. durum (Desf.) Husn.] is a tetraploid species with genome including an A genome of Triticum urartu and a B genome of probably Aegilops speltoides. Bread wheat (Triticum aestivum L. subsp. aestivum) is a hexaploid species with genome including an $\mathrm{AB}$ genome of durum wheat and a D genome of Aegilops tauschii Coss (Chantret et al., 2005). Cultivated hexaploid triticale (X Triticosecale Wittmack), is an artificially created cereal, resulting from the crossing of wheat ( $T$. aestivum L. subsp. aestivum) or durum wheat ( $T$. turgidum L. subsp. durum) with rye (Secale cereale L.); this includes the A and B genomes of Triticum and R of Secale (Eudes, 2015). Cereals also differ in their susceptibility to fungal diseases.

In view of food safety, it is important to monitor the microbial status of grain. In natural conditions cereals can be infested by numerous pathogens, of which fungi are among the most important. Some of them, such as fungi from the genus Fusarium, can cause devastating diseases. These lead to severe economic losses by reducing the grain yield and quality by contamination with mycotoxins which are harmful not only for plants but also animals and humans.

Among the mycotoxins groups described in the literature much attention is focused on a small number of mycotoxins due to their high frequency of occurrence. These include trichothecenes group B with the most commonly occurring deoxynivalenol (DON) (Stępień and Chełkowski, 2010). Trichothecene biosynthesis by fungi is controlled by many factors. The main factor is genetic, determining both, the quantity and quality of created toxins. Related to this is the effect of the different chemotypes of fungi (Lee et al., 2002; Kulik, 2011; Mugrabi de Kuppler et al., 2011) which are often regional in nature (Logrieco and Visconti, 2004). Factors influencing the formation of trichothecenes are: substrate, the time of infection, competition between microorganism, plant-pathogen interaction, and overall climatic conditions among which temperature, humidity, and rainfall are the most important (Champeil et al., 2004). The complexity of the trichothecenes biosynthesis is one of the reasons for the controversy regarding their participation in pathogenesis because trichothecenes are not essential for infection (Hestbjerg et al., 2002). However, some studies have shown that trichothecenes contribute to the virulence of Fusarium (Proctor et al., 2002; Ayumi and Manickavelu, 2015), mainly due to the inhibition of protein synthesis (Mitterbauer et al., 2004). All this information, together with the fact that in the case of various types of cereals we have to deal with the diversity of their resistance to FHB, means that descriptions of new types of resistance are often observed. The influence of trichothecenes on FHB is related to the second type of resistance described for wheat (Schroeder and Christensen,
1963) and resistance to the accumulation of trichothecenes through metabolic transformation (Boutigny et al., 2008).

Metabolomics, a relatively new field of knowledge, provides more and more opportunities to examine the plant metabolome, including cereals (Balmer et al., 2013). An extremely important aspect of these studies is connected with analyses of metabolomic profiles of microorganisms, particularly pathogenic, and toxigenic (Panagiotou et al., 2005), with a significant role being played by those metabolites which, being formed in grain, are frequently precursors for the formation of others (Perkowski et al., 2008a). Of these the most frequently analyzed metabolites to date are ergosterol (ERG) (Müller and Schwadorf, 1999; Perkowski et al., 2008b) and to a lesser extent ATP (Suberkropp et al., 1993; Perkowski et al., 2007).

ERG analysis as the primary sterol of fungal cell membranes has proven useful with respect to both the native fungal biomass and dead. The latter is particularly important in the case of infection by toxigenic fungi such as Fusarium whose products, known as fusariotoxins, are typically very stable and remain in plant tissues, including the grain even in the absence of the longer-lived hyphae of the fungus. In a previous work also by the authors of this paper, it was shown that especially in conditions of massive infection, which takes place during the inoculation of plant with fungus, there is a significant correlation between the concentration of the ERG, and the concentration of trichothecenes (Perkowski et al., 2007). However, in conditions of natural infestation, which highlight the role of other factors, particularly agro-meteorological and the defense mechanisms of plants, the obtained values of correlation coefficients of ERG with trichothecenes often proved to be statistically insignificant. The use of ATP measurements to assess the amount of fungal biomass in the seed is not widespread, although it is a commonly applied method in industry and environmental studies. Essentially it is possible to isolate the ATP from the surface of grains and determine the level of total living biomass. Work conducted previously, particularly in inoculation experiments has revealed a significant correlation of surface ATP levels, with both the concentration of the ERG and trichothecenes (Perkowski et al., 2007).

From the numerous (metabolomic) studies on this subject it seems advisable to select the metabolic pathway proposed by Magan and Evans (2000) as the basis for discussion. This indicates the relationships between individual groups of compounds, i.e., volatiles, non-volatiles, fungal biomass indicators and mycotoxins, and shows volatile compounds to have an inhibitory effect on the growth of other microscopic fungi (Mellon et al., 2002, 2005).

The study of the volatile compound profile allowed for the distinction of individual species of fungi from the genera Penicillium and Aspergillus (Sahgal et al., 2007). Moreover, analyses were also conducted on profiles of volatile compounds formed by fungi from the genus Fusarium (Borjesson et al., 1992; Jeleń and Wąsowicz, 1998; Schnürer et al., 1999; Demyttenaere et al., 2003) From the entire spectrum of volatile compounds produced by these fungi, we particularly need to focus on trichodiene, since, being a secondary metabolite, it is considered as a precursor in the trichothecene biosynthesis pathway 
(Kimura et al., 2003; Perkowski et al., 2008a). Examinations of metabolites which are considered as fungal biomass markersERG and ATP are also of great importance. What is most interesting are the results that indicate a correlation between these markers and mycotoxins (Borjesson et al., 1992; Perkowski et al., 2007) and their relationship with volatile compounds (Demyttenaere et al., 2004; Sahgal et al., 2007; Girotti et al., 2012; Buśko et al., 2014).

The observations presented above and studies conducted to date confirm the applicability of analyses of volatile compounds in the classification of grain depending on the degree of infestation by fungi or even the determination of grain contaminated with mycotoxins. Efforts to accomplish the abovementioned goals were also conducted by means of a set of sensors called an electronic nose (Borjesson et al., 1996). However, under natural conditions the volatiles profile of grain consists of metabolites of kernel as well as microbiota living on its surface. Thus, the examination of volatile organic compounds requires the appropriate natural conditions.

The aim of this study was to determine the VOCs and concentration of trichothecenes group B and mycobiota (ERG, ATP) in a representative sample of 16 genotypes of related cereals: triticale, bread wheat, and durum wheat. Special emphasis was placed on the performance of their comprehensive analysis as well as on an attempt to define the relationship between these parameters. Another objective was to determine the individual compounds differentiating grain of each cereal using chemometric analysis. Such a study in this respect, covering chemical analyses using different techniques (GC/MS, HPLC, luminometric, and the electronic nose), as well as analysing a large population of samples grown at the same time and under identical conditions, both climatic and agronomic, has not been presented to date.

\section{MATERIALS AND METHODS}

In order to distinguish the analyzed cereals thoroughly, a moving statistical analysis was conducted based on metabolites present in cereals. The model allows for the subsequent implementation of different variables representing particular groups of chemical compounds such as Fusarium toxins, ergosterol (ERG), ATP and volatile compounds (VOCs).

\section{Material}

Analyses were conducted on representative naturally contaminated samples of grain: spring triticale (16 genotypes), bread wheat (16 genotypes), and durum wheat (16 genotypes).

The genotypes comprised the most important cultivars regionalized in Poland-tested in state-commissioned trials.

Samples of bread wheat, triticale, and durum wheat were sown in a field experiment at the Plant Breeding and Acclimatization Institute in Radzików (central Poland) (GPS coordinates: $52.211754,20.631954)$. Bread wheat and triticale were cereal varieties listed in the Polish National List of Agricultural Plant Varieties drawn up by the Research Centre for Cultivar Testing (COBORU http://www.coboru.pl). The sample of durum wheat was the only variant located in the registry (in the National List) and 15 advanced breeding lines.
Field experiments were established in a randomized block design. The cereals were sown in plots with an area of $10 \mathrm{~m}^{2}$, in triplicate. No fungicides were used during cultivation. Plants were grown and harvested in accordance with good agricultural practice standards under identical environmental conditions.

After ripening (BBCH 89), 500 heads were harvested manually from each plot and threshed with a laboratory thresher at a low wind speed to prevent loss of low-weight infected kernels. The percentage of damaged kernels was assessed visually (results not presented in this work). Grain samples of three reps (an aliquot of grains of $1 \mathrm{~kg}$ ) were obtained. Immediately after harvest the profile of volatile compounds was analyzed together with the concentration of ERG, ATP, and trichothecenes. The results are expressed as the dry weight of the grain.

\section{Analysis of VOCs}

Analysis of VOCs was performed as described by Buśko et al. (2010). VOCs were extracted from grain using the solid-phase microextraction method (SPME). Grain samples $(8 \mathrm{~g})$ were placed in $20 \mathrm{ml}$ vials and extracted by means of headspace SPME for $30 \mathrm{~min}$ at $50^{\circ} \mathrm{C}$ with $200 \mathrm{~mm}-53 / 30 \mu \mathrm{m}$ divinylbenzene/Carboxene/polydimethylsiloxane StableFlexTM (DVB/Carboxen/PDMS) fiber. The analyses were run on a gas chromatograph (Agilent 7890A) hyphenated to a mass spectrometer (TruTOF HT, LECO), using an RTX-5 (0.20 mm $\times 10 \mathrm{~m}$ ) capillary column. The injection port temperature was $260^{\circ} \mathrm{C}$, the transfer line temperature was $280^{\circ} \mathrm{C}$ and the analyses were performed with a programmed temperature: initial $40^{\circ} \mathrm{C}$ held for $1 \mathrm{~min}$, from $40^{\circ} \mathrm{C}$ to $180^{\circ} \mathrm{C}$ at $10^{\circ} \mathrm{C} / \mathrm{min}, 180$ to $260^{\circ} \mathrm{C}$ at $40^{\circ} \mathrm{C} / \mathrm{min}$. The helium flow rate was held constant at 0.8 $\mathrm{ml} / \mathrm{min}$. Spectra were acquired at $50 \mathrm{spectra} / \mathrm{s}$ within a range of 30-380 Da. The detector voltage was $2500 \mathrm{~V}$, electron energy $70 \mathrm{eV}$. The amount of VOCs was estimated by comparing the area of their total ion current (TIC) peaks with the internal standard (addition of $25 \mathrm{ng}$ of tridecane in pentane) and expressed as their ratio (RU). Compounds were identified by comparing their mass spectra with spectra from the NBS $75 \mathrm{~K}$ and NIST 98 libraries and retention indices were compared to data available in the literature. Retention indices were calculated based on a chromatographic analysis of chain alkanes (C4-C20)

\section{Electronic Nose}

The electronic nose was used to analyse mixtures of volatile substances, characterizing samples, and facilitating their identification as described in Perkowski et al. (2012). They were identified by comparing sample characteristics with the matrix recorded in the computer memory. The procedure for the application of the "electronic nose" is based on the direct analysis of a mixture of volatile compounds collected from samples with the headspace technique, transferred from the automatic injection port in a quadrupole mass spectrometer. In the headspace technique, by applying optimal conditions (temperature and time), the gas phase is obtained, whose composition in terms of quantity and quality reflects the composition of the original sample. Analyses were performed with a Perkin-Elmer apparatus, an HKR Sensorsysteme with TM SOFT NT and QMB SOFT NT software by HKR 
Sensorsysteme, using statistical discriminatory analysis to facilitate differentiation of products and graphic presentation of results. In all cases the analysis of a sample was performed in at least 10 replications, making it possible to obtain a mean value, most accurately corresponding to the analyzed sample.

\section{Analysis of Trichothecenes}

Samples of grain were analyzed according to Perkowski et al. (2003). Briefly, samples (10 g) were extracted with acetonitrile/water (82:18) and cleaned-up on a charcoal column [Celite 545/charcoal Draco G/60/activated alumina neutral 3:9:5 (w/w/w)].

Trichothecene toxins of group B (DON, 3-AcDON, 15AcDON, FUS X, NIV; Sigma, St. Louis, USA) after derivatization with mixture of trimethylsilylimidazole - trichlorosilane (100$1 \mathrm{v} / \mathrm{v}$ ) were analyzed by a mean gas chromatograph (Hewlett Packard GC 6890) coupled to a mass spectrometer (Hewlett Packard 5972 A, Waldbronn, Germany), using an HP-5MS, 0.25 $\mathrm{mm} \times 30 \mathrm{~m}$ capillary column. The samples were injected into the injection port (at $250^{\circ} \mathrm{C}$ ), the transfer line temperature was $280^{\circ} \mathrm{C}$ and the analyses were performed with the programmed temperature: initial temperature $80^{\circ} \mathrm{C}$, held $1 \mathrm{~min}$, from $80^{\circ} \mathrm{C}$ to $200^{\circ} \mathrm{C}$ at $15^{\circ} \mathrm{C} / \mathrm{min}$ held $6 \mathrm{~min}$ and from $200^{\circ} \mathrm{C}$ to $280^{\circ} \mathrm{C}$ at $10^{\circ} \mathrm{C} / \mathrm{min}$, the final temperature being maintained for $3 \mathrm{~min}$. The helium flow rate was constant at $0.7 \mathrm{ml} / \mathrm{min}$. Quantitative analysis was performed with the external standard method in single ion monitored mode (SIM) using the following ions for the detection of DON: 103 and 512; 3-AcDON: 117 and 482; 15-AcDON: 193 and 482; FUS X: 103 and 570; NIV: 191 and 600. Recovery for analyzed toxins was as follows: DON, $84 \pm$ $3.8 \%$; 3 AcDON, $78 \pm 4.8 \%$; 15Ac-DON, $74 \pm 2.2 \%$; FUS X, $87 \pm$ $5.9 \%$; NIV, $81 \pm 3.8 \%$. The limit of detection was $0.01 \mu \mathrm{g} / \mathrm{kg}$. Qualitative analysis was performed in SCAN mode (100-700 $\mathrm{amu}$ ).

\section{Analysis of Ergosterol}

ERG was determined by HPLC as described by Perkowski et al. (2008b). Samples containing $100 \mathrm{mg}$ of ground grains were placed into $17-\mathrm{ml}$ culture tubes, suspended in $2 \mathrm{ml}$ of methanol, treated with $0.5 \mathrm{ml}$ of $2 \mathrm{M}$ aqueous sodium hydroxide, and tightly sealed. The culture tubes were then placed within 250$\mathrm{ml}$ plastic bottles, tightly sealed and placed inside a microwave oven (Model AVM 401/1WH, Whirlpool, Sweden) operating at $2450 \mathrm{MHz}$ and $900 \mathrm{~W}$ maximum output. Samples were irradiated $(370 \mathrm{~W})$ for $20 \mathrm{~s}$ and after $\sim 5 \mathrm{~min}$ for an additional $20 \mathrm{~s}$. After 15 min the contents of the culture tubes were neutralized with $1 \mathrm{M}$ aqueous hydrochloric acid, $2 \mathrm{ml} \mathrm{MeOH}$ were added and extraction with pentane $(3 \times 4 \mathrm{ml})$ was carried out within the culture tubes. The combined pentane extracts were evaporated to dryness in a nitrogen stream. Before analysis samples were dissolved in $4 \mathrm{ml}$ of $\mathrm{MeOH}$, filtered through 13-mm syringe filters with a $0.5 \mu \mathrm{m}$ pore diameter (Fluoropore Membrane Filters, Millipore, Ireland) and evaporated to dryness into an $\mathrm{N}_{2}$ stream. The sample extract was dissolved in $1 \mathrm{ml}$ of $\mathrm{MeOH}$ and $50 \mu \mathrm{l}$ were analyzed using an HPLC technique. Chromatographic separation was done on a $150 \times 3.9 \times 4 \mathrm{~mm}$ Nova Pak $\mathrm{C}-18$ column and eluted with methanol/acetonitrile $(90: 10)$ at a flow rate of 0.6 $\mathrm{ml} / \mathrm{min}$. Detection was performed by means of a Waters 486 Tunable Absorbance Detector (Milford, MA, USA) set at $282 \mathrm{~nm}$. Conformation of the presence of ERG was based on a comparison of retention times and the co-injection of every tenth sample with an ERG standard. The limit of detection was $0.02 \mathrm{mg} / \mathrm{kg}$ for the method.

\section{Analysis of ATP}

Determination of ATP was performed according to Perkowski et al. (2012). ATP was extracted from the surface of a $1.00 \mathrm{~g}$ sample of kernels, using boiling tris buffer $(8 \mathrm{ml}, 0.1 \mathrm{M}$ solution, $\mathrm{pH}$-7.75). After which $100 \mu \mathrm{l}$ of the cooled extract was added to $100 \mu \mathrm{l}$ reagent [luciferin and luciferase eLuminATE (QM) from the Microbial Biomass kit supplied by Celsis, Netherlands]. The light emission was measured by a Lumac Biocounter M 1500 luminometer and read as Relative Light Units (RLU). The emitted light correlates with the amount of ATP in the sample as reported by Suberkropp et al. (1993).

\section{Statistical Analysis}

The results recorded in the course of the conducted chemical analyses were subjected to statistical analysis with the use of STATISTICA ver. 8.0 (StatSoft, Inc., Tulsa, OK, USA) and Microsoft ${ }^{\circledR}$ Excel 2010/XLSTAT@-Pro Version 2015.1.02 (Addinsoft, Inc., Brooklyn, NY, USA) software packages. In order to compare contents of volatile compounds in samples Tukey's multiple comparison procedure was used, with identical letters in rows or columns denoting a lack of differences at the significance level $P=0.05$. Moreover, a step linear discriminatory analysis (SLDA) and the principal component analysis (PCA) were used in order to separate groups of analyzed populations. Additionally, the classification matrix and multivariate significance tests were applied. On the basis of cluster analysis heatmaps were prepared, with marked regions differentiating analyzed groups at the confidence level $P=0.05$.

\section{RESULTS}

The significantly highest concentration of ERG was determined in triticale, it was lower in bread wheat and the lowest in durum wheat (Table 1). The second indicator of microbial contamination of grain was ATP, which only allows the level of the surface contamination with living cells to be determined. The ATP levels were found to be significantly different only for durum wheat. Bread wheat and triticale did not significantly differ from each other in terms of ATP concentrations as shown in Table 1. The determined concentration of group B trichothecene mycotoxins is shown in Table 1. The concentration of the sum was highest for durum wheat, with $<50 \%$ for bread wheat and approx. $70 \%$ for triticale relative to durum wheat, the only significant differences were observed between durum wheat and triticale. Among the four analyzed mycotoxins DON was found to have the largest share in the total concentrations of trichothecenes for durum wheat, $75 \%$ and bread wheat up to $82 \%$, the highest concentration being respectively 116.94 $\mu \mathrm{g} / \mathrm{kg}$ and $55.69 \mu \mathrm{g} / \mathrm{kg}$. The concentration of acyl derivatives 


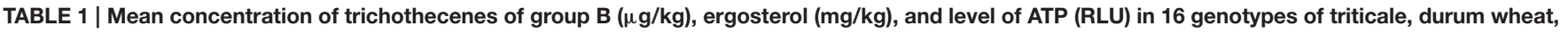
and bread wheat.

\begin{tabular}{|c|c|c|c|c|c|c|c|c|c|}
\hline \multirow[t]{2}{*}{ Compound } & \multicolumn{3}{|c|}{ Triticale } & \multicolumn{3}{|c|}{ Durum wheat } & \multicolumn{3}{|c|}{ Bread wheat } \\
\hline & Mean & SE & Positive samples & Mean & SE & Positive samples & Mean & SE & Positive samples \\
\hline DON & $16.98^{\mathrm{a}}$ & 6.34 & 94 & $116.94^{b}$ & 38.12 & 94 & $55.69^{a b}$ & 24.12 & 81 \\
\hline 3-AcDON & $24.76^{b}$ & 3.05 & 100 & $5.29^{a}$ & 1.58 & 50 & $4.68^{a}$ & 0.98 & 81 \\
\hline 15-AcDON & $0.38^{a}$ & 0.18 & 25 & $0.40^{a}$ & 0.15 & 31 & $2.02^{a}$ & 0.88 & 56 \\
\hline NIV & $4.61^{a}$ & 1.31 & 56 & $32.32^{b}$ & 10.92 & 81 & $5.12^{a}$ & 1.60 & 56 \\
\hline SumTox & $46.74^{\mathrm{a}}$ & 8.51 & & $154.95^{\mathrm{b}}$ & 44.21 & & $67.51^{\mathrm{ab}}$ & 24.53 & \\
\hline ERG & $5.28^{C}$ & 0.35 & & $2.30^{a}$ & 0.26 & & $3.41^{b}$ & 0.35 & \\
\hline ATP & $50,744^{a}$ & 3211 & & $23,3015^{b}$ & 33,123 & & $97,605^{a}$ & 13,961 & \\
\hline
\end{tabular}

Values in separate columns marked with the same letter $(a, b, c)$ do not differ significantly at $p=0.05$, according to HSD Tukey test.

SE-standard error, positive samples-\%.

of DON in trials in/on cereals was low and not statistically different. As indicated above, the lowest level of tested DON was found for triticale, although it was characterized by a fivefold higher concentration of 3-AcDON than the other cereals. Accordingly, it is the $3-\mathrm{AcDON}$ toxin that was dominant and the concentration of DON here was more than $30 \%$ lower than the concentration of 3-AcDON. The highest concentration of NIV was determined in the durum wheat, the toxin being identified in $81 \%$ of the trials. The analyzed NIV concentration in the other two species of cereals was nearly eight-fold lower, and designated in $56 \%$ of trials. Based on the results of chemical analyses, a correlation analysis was performed (Table 2). Obtained correlation matrices showed the greatest contribution to the correlation of toxins in the case of the entire population of samples, and an inversely proportional correlation was revealed between the concentration of toxins, and the concentration of the ERG. The highest correlation with concentrations of toxins summary for all tested species of cereals was the predominant toxin-DON. However, highly significant correlations were also observed in the case of cereals particularly when considered separately (Figure 1). An example is that the means of all the analyzed cereals differ significantly in ERG/ATP ratio. This is due to the fact that the level of contaminating mycobiota was characteristic for individual cereal species. This indicates that a highly significant correlation coefficient exists for ERG and ATP: for a single species of triticale grain, respectively: $0.947^{* * *}$; durum wheat: $0.810^{* * *}$; wheat bread: $0.932^{* * *}$, but if the entire population of grain was not negligible.

The above-mentioned metabolites account for a further discrimination of the examined cereals. Microscopic fungi produce a variety of volatile compounds through their metabolism. Analysis of the presence of volatile compounds in the examined cereals revealed a broad spectrum of VOCs, comprising over 1600 signals. These signals (a combination of the retention index and unique ions) were found in different cereals at different intensities. Of these, 201 were chosen, whose incidence in individual grain samples exceeded $40 \%$, as shown in Figure 2. A total of 46 volatile compounds were identified (Table 3). These 46 compounds were detected in all analyzed samples of particular cereals. They belonged to five different
TABLE 2 | Coefficients of Pearson correlations between ATP, ERG, and trichothecene mycotoxins for three cereals $(n=16)$ and for all $(n=48)$ analyzed cereals samples (Total).

\begin{tabular}{|c|c|c|c|c|c|c|}
\hline & ATP & ERG & DON & 3-AcDON & 15-AcDON & NIV \\
\hline \multicolumn{7}{|l|}{ TRITICALE } \\
\hline ERG & $0.947^{\star \star \star}$ & & & & & \\
\hline DON & 0.438 & 0.253 & & & & \\
\hline 3-AcDON & 0.430 & 0.367 & 0.347 & & & \\
\hline 15-AcDON & -0.017 & 0.105 & 0.103 & $0.708^{\star \star}$ & & \\
\hline NIV & 0.474 & 0.404 & 0.253 & 0.374 & 0.284 & \\
\hline SumTox & $0.553^{\star}$ & 0.380 & $0.906^{\star \star \star}$ & $0.687^{\star \star}$ & 0.242 & 0.482 \\
\hline \multicolumn{7}{|c|}{ DURUM WHEAT } \\
\hline ERG & $0.810^{\star \star \star}$ & & & & & \\
\hline DON & 0.084 & -0.110 & & & & \\
\hline 3-AcDON & 0.060 & -0.182 & -0.122 & & & \\
\hline 15-AcDON & 0.142 & 0.044 & 0.060 & 0.209 & & \\
\hline NIV & 0.475 & -0.138 & 0.488 & -0.343 & -0.179 & \\
\hline SumTox & 0.187 & -0.135 & $0.979^{\star \star \star}$ & -0.154 & 0.019 & $0.655^{\star \star}$ \\
\hline \multicolumn{7}{|c|}{ BREAD WHEAT } \\
\hline ERG & $0.932^{\star \star \star}$ & & & & & \\
\hline DON & -0.336 & -0.393 & & & & \\
\hline 3-AcDON & -0.369 & -0.458 & 0.497 & & & \\
\hline 15-AcDON & -0.214 & -0.391 & -0.035 & 0.164 & & \\
\hline NIV & -0.189 & -0.240 & -0.098 & 0.027 & 0.164 & \\
\hline SumTox & -0.365 & -0.435 & $0.996^{\star \star \star}$ & $0.543^{\star}$ & 0.027 & -0.024 \\
\hline \multicolumn{7}{|c|}{ TOTAL SAMPLES } \\
\hline ERG & -0.121 & & & & & \\
\hline DON & 0.171 & $-0.353^{\star}$ & & & & \\
\hline 3-AcDON & $-0.349^{\star}$ & $0.528^{\star \star \star}$ & -0.180 & & & \\
\hline 15-AcDON & -0.102 & -0.201 & -0.026 & -0.001 & & \\
\hline NIV & 0.033 & $-0.293^{\star}$ & $0.488^{\star \star \star}$ & -0.236 & -0.078 & \\
\hline SumTox & 0.123 & $-0.331^{\star}$ & $0.979^{\star \star \star}$ & -0.114 & -0.023 & $0.634^{* \star *}$ \\
\hline
\end{tabular}

*Value significant at $p=0.05 ;{ }^{* *}$ value significant at $p=0.01 ;{ }^{* \star *}$ value significant at $p=$ 0.001 .

chemical groups-alcohols, aldehydes and ketones, benzene derivatives, hydrocarbons, and terpenes-and also to a sixth group, designated as "others"-butyrolactone, dimethyl sulfone, octanoic acid, 5-butyldihydro-2-(3H)-furanone, nonanoic 


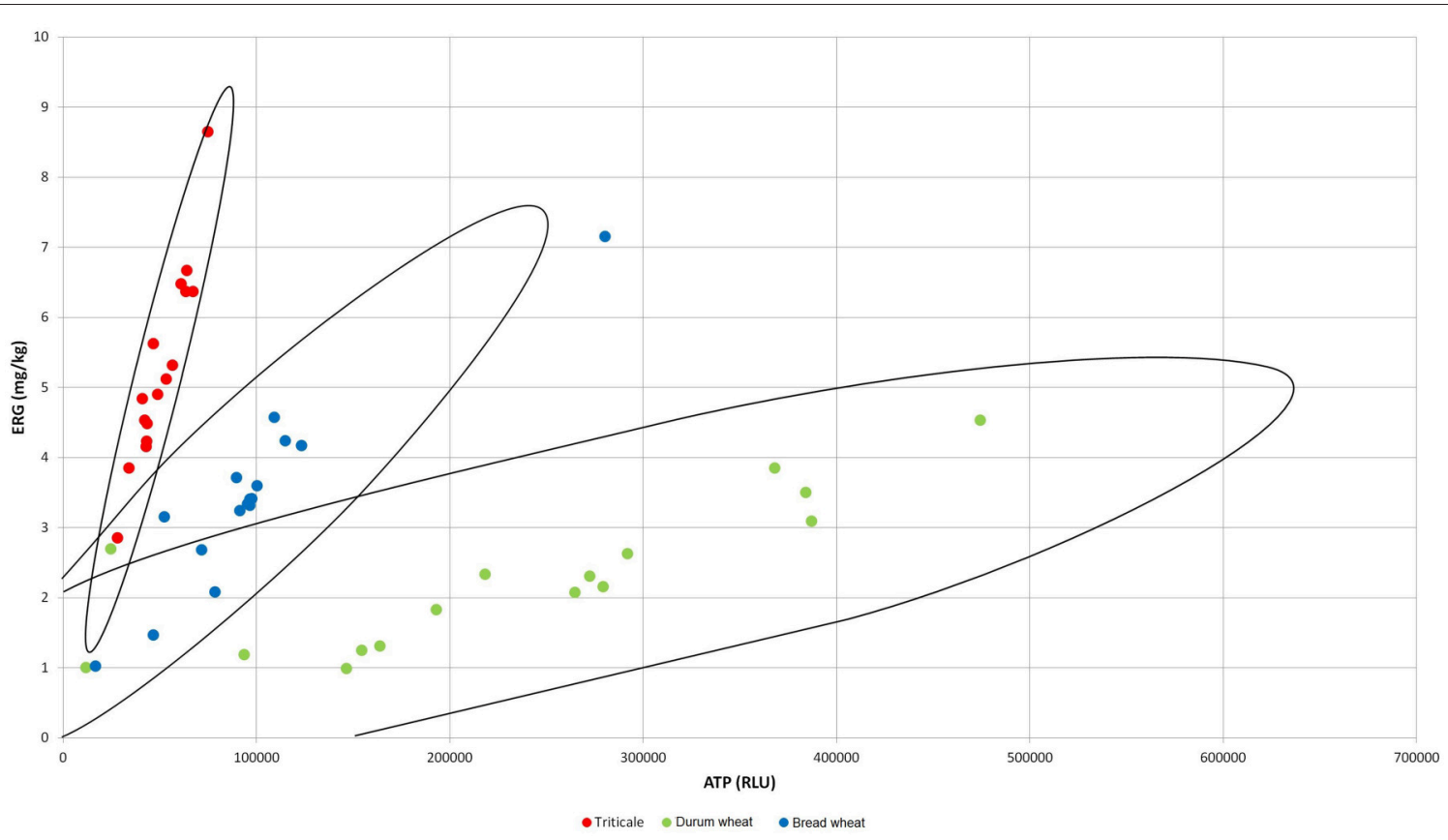

FIGURE 1 | Correlation between ERG concentration $(\mathrm{mg} / \mathrm{kg})$ and ATP level (RLU) for triticale, bread wheat, and durum wheat.

acid, and diethyl phthalate (Table 3). The most numerous compounds were alcohols. This group of volatiles was present in the highest amount in bread wheat, as presented in Figure 2, although a significant difference was found only between bread wheat and triticale (Table 3). The next most abundant group comprised benzene derivatives, amounts of which were significantly different between particular cereals; the highest amount was found in durum wheat, followed by triticale, and the lowest in bread wheat (Figure 2). Significantly (twofold) higher levels of aldehydes and ketones were observed in samples of bread wheat. In the case of hydrocarbons the highest percent content was noted for durum wheat, but this did not differ significantly from bread wheat. Although the lowest share among volatile compounds was found for terpenes, their percentages for all three cereals were statistically different (Table 3).

Tukey's test was carried out based on the results of the analysis of VOCs. From 201 compounds 15 VOCs (Figure 3) were significantly different in all grains. A subsequent stepwise discriminant analysis (SDA) was performed for only those 15 compounds (Figure 4A). Among them, the factors of greater power of discrimination were: lilial, trichodiene, and p-xylene. On the basis of the determined classification functions covering all the variables, test subjects were classified into groups concerned with correctness at different levels of $\sim 90 \%$.

Similarities and differences which characterized three cereal species suggested the advisability of conducting an analysis to separate these cereals depending on the percentages of combinations of retention indexes and ions. In order to visualize the relationships and differences in VOC levels for each sample, heatmaps (Figure 5) for metabolite profiles in new leaves were used.

To identify differences between the trial populations based on the concentration of volatile compounds, a comparative analysis of multi-dimensional objects and attributes was carried out. Detailed presentation of the distribution of important volatiles in the three analyzed cereals was accomplished with a heatmap. This helped to assess the extent to which the sample was characterized by the concentration of determined compounds. A similar color tone to the heatmap indicates the area-a group of sampleswhich based on the concentration of the analyzed compounds is homogeneous. This analysis clearly shows that the identified volatile compounds are discriminants under which objects can be assigned to the appropriate groups depending on the level of concentration of these compounds (fields marked $*$ in the heatmap).

Based on these premises, the analysis of the three cereals was conducted. The aim of the modeled experiment was to comprehensively distinguish analyzed cereals by means of statistical analyses of the content of trichothecenes group B, ERG, ATP, and VOCs. In order to investigate the relationship between trichothecenes and the examined cereals we conducted PCA. The results are presented in Figure 6A. The first two principal components explained $65.88 \%$ of variability of the data. Based on the correlation circle, the first component (F1) was highly positively correlated with DON and NIV, and highly negatively correlated with 3 -AcDON. The second component (F2) was highly positively correlated with 15-AcDON. Analysing observations in the same figure, where only the first two components are considered, some discrimination of cereals can be stated. Durum wheat samples tend to be located on the 


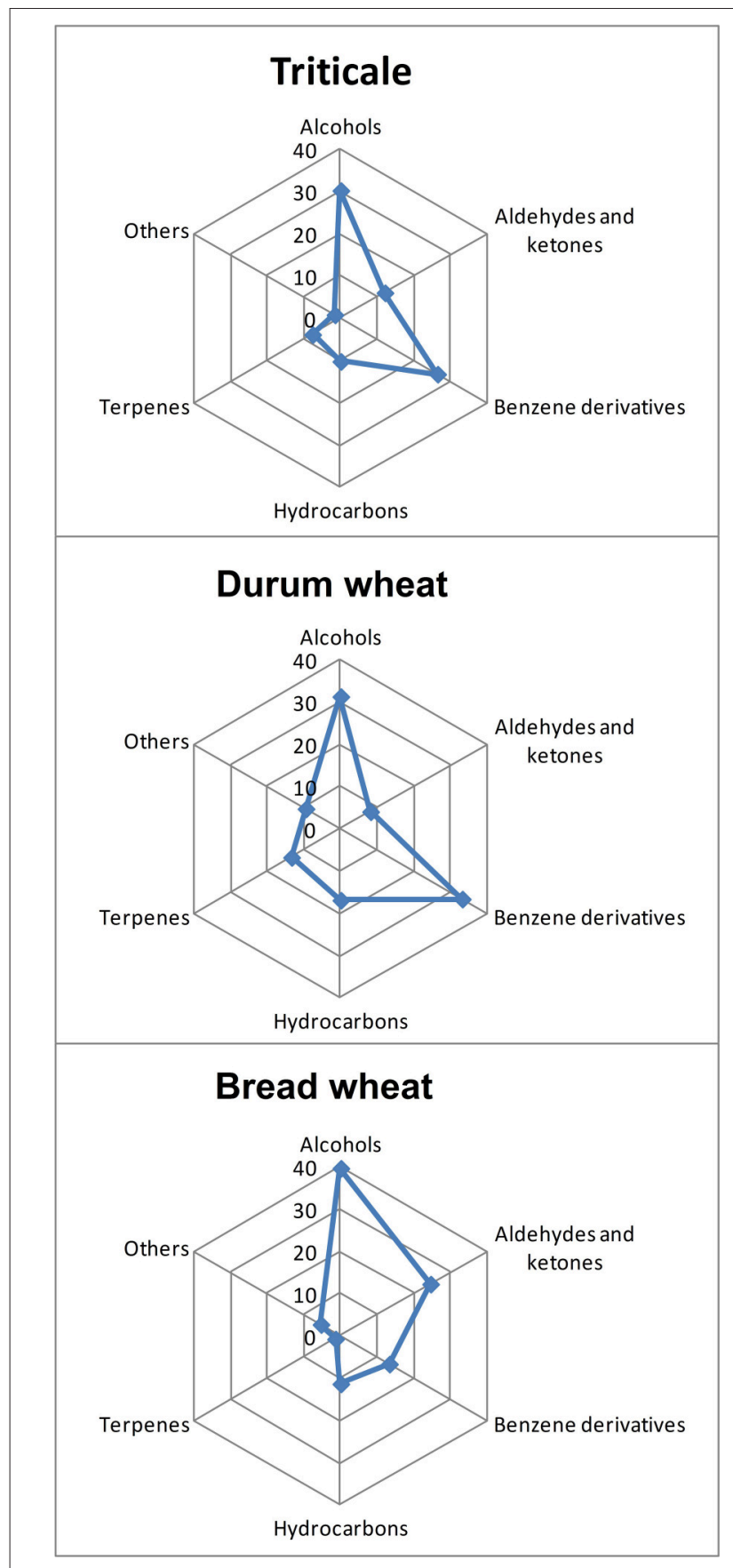

FIGURE 2 | Mean percentage contents of volatile compounds differentiating triticale, bread wheat, and durum wheat.

right part of the $\mathrm{F} 1$ axis, while triticale tends to be located on the left side of the F1 axis and the lower part of the F2 axis. Close to them but closer to the middle point the bread wheat samples are located. However, since the percentage of variability represented by the two factors is not very high (65.88\%), to avoid a misinterpretation of the results, we decided to complement them. Analysing squared cosines of the observations, pointed to an important role of the F3 factor. Moreover, triticale samples, like the variable 3-AcDON, are located in the upper part of the F3 axis, above the F1/F2 plane, while bread wheat tends to be located in the lower part of the F3 axis, below the F1/F2 plane. Thus, considering the three factors (F1, F2, F3), better discrimination of cereals seems possible.

The analysis was then extended with an analysis of ERG and ATP (Figure 6B), which are fungal biomass indicators, and subsequently compared with the level of VOCs in grain. The distribution of variables was similar to that of mycotoxins only, but variables DON and NIV were supplemented with the variable ATP, and the variable $3-A c D O N$ was accompanied by ERG. Such a set of variables resulted in a distribution of observations mainly along the F1 axis. Also, as in the case of previous PCA analysis, the location of triticale corresponded to 3-AcDON and ERG, and durum wheat to DON, NIV, and ATP. However, some durum samples, like most of the bread wheat samples, were close to the center. The last PCA was performed for all analyzed variables, i.e., trichothecenes, ERG, ATP, and VOCs (Figures 6C,D). Distribution of variables indicates that most of the VOCs have a stronger impact on the distribution of observations than DON, NIV, and ATP. In this case, durum wheat observations were located below the F2 axis and tended to be located on the right side as DON, NIV, ATP, and almost half of the VOC variables. Triticale observations were located mainly on the left side of the F1 axis but close to the F2 axis. Similarly located were 3-AcDON, ERG, dimethyl sulfone, and styrene, but VOCs were very close to the center. Bread wheat observations were situated above the F2 axis, and only some of them were on the right side of the F1 axis, where almost half of the VOCs were located. Generally, the distribution of observations suggests high diversity among each analyzed cereal group. Since the impact of VOCs on the distribution of observations was higher than that of trichothecenes, ERG and ATP, the pattern of distribution of observations for PCA for all variables is similar to PCA for VOCs only (figure not presented).

The subsequent analytical step after PCA was a discriminant analysis (DA) to determine the compounds that best separate the three cereal species. Initially, an analysis including trichothecenes was performed (Figure 7A). The inclusion of all four of the most important mycotoxins in the model allowed for $66.67 \%$ discrimination of cereals into groups. Extension of variables to incorporate fungal biomass markers, i.e., ERG and ATP, resulted in an increase of total discrimination up to $93.75 \%$ (Figure 7B). However, in this analysis the highest discriminant power was shown by 3 -AcDON, ERG, and ATP. After completing the variables with VOCs, the obtained model allowed for the discrimination of analyzed cereals into groups at $97.92 \%$ (Figure 7C) since only one sample of triticale was posterior classified as bread wheat. As the forward selection method was applied, the model included the following compounds: limonene, lilial, 3-AcDON, 1-decanol, p-xylene, triacontane, NIV, cymene, dodecane, 1-heptanol, dimethyl sulfone, and nonanoic acid (Figure 7D).

The performed DA which took into account all 46 of the 201 generally identified VOCs, resulted in the complete discrimination of the analyzed cereals into three groups based 
TABLE 3 | Qualitative and quantitative (RU) profile of 46 volatile metabolites for 16 genotypes of triticale, durum wheat, and bread wheat.

\begin{tabular}{|c|c|c|c|c|c|c|c|c|}
\hline Lp & $\mathbf{R I}$ & Compound & Triticale & Durum wheat & Bread wheat & Metabolite group & Wilk's lambda & F displacement \\
\hline 1 & 870 & $\mathrm{p}-\mathrm{Xylene^{* }}$ & $1.486^{\mathrm{C}}$ & $0.539^{b}$ & $0.283^{a}$ & Benzene derivatives & 0.237 & 5.964 \\
\hline 2 & 873 & 1-Hexanol & $3.512^{\mathrm{a}}$ & $5.210^{b}$ & $3.732^{\mathrm{a}}$ & Alcohols & & \\
\hline 3 & 889 & Styrene & $0.173^{a}$ & $0.077^{a}$ & $0.046^{a}$ & Benzene derivatives & & \\
\hline 4 & 901 & Heptanal$^{\star}$ & $0.328^{a}$ & $0.392^{a}$ & $0.561^{b}$ & Aldehydes and ketones & 0.460 & 1.984 \\
\hline 5 & 916 & Butyrolactone & $0.690^{\mathrm{a}}$ & $1.529^{b}$ & $0.815^{\mathrm{a}}$ & Others & & \\
\hline 6 & 927 & Dimethyl sulfone & $0.001^{\mathrm{a}}$ & $0.000^{\mathrm{a}}$ & $0.000^{\mathrm{a}}$ & Others & & \\
\hline 7 & 929 & Alpha-Pinene & $0.158^{a}$ & $0.611^{\mathrm{b}}$ & $0.067^{a}$ & Terpenes & & \\
\hline 8 & 948 & Propylbenzene & $0.450^{a}$ & $0.926^{b}$ & $0.437^{a}$ & Benzene derivatives & & \\
\hline 9 & 957 & 1-ethyl-2-methylbenzene & $1.289^{\mathrm{a}}$ & $3.422^{b}$ & $0.956^{a}$ & Benzene derivatives & & \\
\hline 10 & 963 & 1.3.5-trimethylbenzene & $0.299^{a}$ & $0.668^{b}$ & $0.288^{a}$ & Benzene derivatives & & \\
\hline 11 & 969 & 1-heptanol* & $0.173^{\mathrm{a}}$ & $0.181^{a}$ & $0.221^{a}$ & Alcohols & 0.245 & 3.156 \\
\hline 12 & 974 & 1-ethyl-3-methyl-benzene* & $0.170^{\mathrm{a}}$ & $0.458^{b}$ & $0.164^{a}$ & Benzene derivatives & 0.879 & 1.174 \\
\hline 13 & 978 & 1-octen-3-ol* & $0.199^{a}$ & $0.303^{b}$ & $0.248^{a}$ & Alcohols & 0.261 & 3.127 \\
\hline 14 & 985 & 6-methyl-5-Hepten-2-one & $0.164^{a}$ & $0.166^{a}$ & $0.220^{\mathrm{a}}$ & Aldehydes and ketones & & \\
\hline 15 & 988 & Benzene & $1.211^{\mathrm{a}}$ & $2.696^{b}$ & $1.060^{\mathrm{a}}$ & Benzene derivatives & & \\
\hline 16 & 989 & 2-octanone & $0.161^{a}$ & $0.335^{\mathrm{b}}$ & $0.321^{b}$ & Aldehydes and ketones & & \\
\hline 17 & 1005 & 3 -carene ${ }^{\star}$ & $0.087^{\mathrm{a}}$ & $0.123^{b}$ & $0.062^{a}$ & Terpenes & 0.554 & 1.845 \\
\hline 18 & 1020 & Cymene & $0.064^{a}$ & $0.185^{b}$ & $0.053^{a}$ & Terpenes & & \\
\hline 19 & 1024 & Limonene & $0.187^{\mathrm{a}}$ & $0.750^{b}$ & $0.165^{\mathrm{a}}$ & Terpenes & & \\
\hline 20 & 1029 & 2-ethyl-1-hexanol & $3.695^{a}$ & $3.403^{a}$ & $3.365^{a}$ & Alcohols & & \\
\hline 21 & 1030 & Indane* & $0.037^{a}$ & $0.056^{a}$ & $0.026^{a}$ & Benzene derivatives & 0.407 & 2.369 \\
\hline 22 & 1038 & 3-octen-2-one & $0.065^{a}$ & $0.082^{a}$ & $0.071^{a}$ & Aldehydes and ketones & & \\
\hline 23 & 1092 & Nonan-2-one & $0.027^{a}$ & $0.039^{a}$ & $0.147^{b}$ & Aldehydes and ketones & & \\
\hline 24 & 1094 & (E.E)-3.5-Octadien-2-one & $0.005^{a}$ & $0.031^{a}$ & $0.042^{a}$ & Aldehydes and ketones & & \\
\hline 25 & 1099 & Undecane* & $0.183^{a}$ & $0.442^{\mathrm{C}}$ & $0.205^{b}$ & Hydrocarbons & 0.404 & 2.554 \\
\hline 26 & 1105 & Nonanal & $0.761^{b}$ & $0.748^{b}$ & $1.523^{a}$ & Aldehydes and ketones & & \\
\hline 27 & 1178 & Naphthalene & $0.450^{b}$ & $0.361^{a}$ & $0.392^{a}$ & Benzene derivatives & & \\
\hline 28 & 1192 & 3.5.5-Trimethylcyclohexen-2-one & $0.007^{\mathrm{a}}$ & $0.000^{\mathrm{a}}$ & $0.059^{a}$ & Aldehydes and ketones & & \\
\hline 29 & 1192 & Octanoic Acid & $0.183^{a}$ & $0.518^{b}$ & $0.148^{a}$ & Others & & \\
\hline 30 & 1199 & Dodecane & $0.278^{a}$ & $0.425^{b}$ & $0.251^{a}$ & Hydrocarbons & & \\
\hline 31 & 1206 & Decanal & $0.258^{a}$ & $0.146^{\mathrm{a}}$ & $0.822^{b}$ & Aldehydes and ketones & & \\
\hline 32 & 1221 & 2-phenoxyethanol* & $0.211^{\mathrm{a}}$ & $0.352^{a}$ & $0.382^{a}$ & Alcohols & 0.315 & 2.493 \\
\hline 33 & 1261 & 5-butyldihydro-2(3H)-furanone & $0.084^{a}$ & $0.097^{a}$ & $0.112^{\mathrm{a}}$ & Others & & \\
\hline 34 & 1276 & 1-decanol ${ }^{\star}$ & $0.099^{a}$ & $0.337^{c}$ & $0.261^{b}$ & Alcohols & 0.349 & 5.871 \\
\hline 35 & 1283 & Nonanoic acid & $0.112^{\mathrm{a}}$ & $0.164^{a}$ & $0.160^{a}$ & Others & & \\
\hline 36 & 1291 & 2-methylnaphthalene* & $0.090^{a}$ & $0.125^{\mathrm{a}}$ & $0.151^{\mathrm{a}}$ & Benzene derivatives & 0.369 & 4.563 \\
\hline 37 & 1308 & 1-methylnaphthalene & $0.076^{a}$ & $0.106^{a}$ & $0.080^{\mathrm{a}}$ & Benzene derivatives & & \\
\hline 38 & 1400 & Tetradecane & $0.457^{\mathrm{a}}$ & $0.650^{b}$ & $0.656^{b}$ & Hydrocarbons & 0.316 & 2.364 \\
\hline 39 & 1456 & (E)-6.10.-dimethyl-5.9-undecadien-2-one & $1.005^{\mathrm{a}}$ & $0.934^{a}$ & $1.538^{b}$ & Aldehydes and ketones & & \\
\hline 40 & 1502 & Pentadecane & $0.547^{a}$ & $0.946^{b}$ & $0.536^{a}$ & Hydrocarbons & & \\
\hline 41 & 1520 & Trichodiene* $^{\star}$ & $0.010^{a}$ & $0.061^{a}$ & $0.031^{a}$ & Terpenes & 0.221 & 5.103 \\
\hline 42 & 1529 & Lilial $^{*}$ & $0.007^{\mathrm{a}}$ & $0.009^{a}$ & $0.033^{\mathrm{a}}$ & Terpenes & 0.412 & 25.055 \\
\hline 43 & 1597 & Diethyl Phthalate & $0.122^{a}$ & $0.249^{b}$ & $0.382^{C}$ & Others & & \\
\hline 44 & 1599 & Hexadecane & $0.524^{a}$ & $0.754^{b}$ & $0.660^{b}$ & Hydrocarbons & & \\
\hline 45 & 1999 & Eicosane & $0.283^{a}$ & $0.332^{b}$ & $0.530^{c}$ & Hydrocarbons & & \\
\hline \multirow[t]{7}{*}{46} & 3007 & Triacontane ${ }^{*}$ & $0.026^{a}$ & $0.057^{\mathrm{a}}$ & $0.073^{a}$ & Hydrocarbons & 0.317 & 2.353 \\
\hline & & Alcohols & $30.17^{a}$ & $31.25^{\mathrm{ab}}$ & $39.61^{b}$ & & & \\
\hline & & Aldehydes and ketones & $12.04^{\mathrm{a}}$ & $8.12^{\mathrm{a}}$ & $24.51^{b}$ & & & \\
\hline & & Benzene derivatives & $26.41^{\mathrm{b}}$ & $33.15^{\mathrm{C}}$ & $13.26^{\mathrm{a}}$ & & & \\
\hline & & Hydrocarbons & $10.20^{a}$ & $16.85^{b}$ & $11.32^{a b}$ & & & \\
\hline & & Terpenes & $7.71^{\mathrm{b}}$ & $13.45^{\mathrm{C}}$ & $1.45^{\mathrm{a}}$ & & & \\
\hline & & Others & $1.61^{\mathrm{a}}$ & $9.51^{\mathrm{C}}$ & $5.42^{\mathrm{b}}$ & & & \\
\hline
\end{tabular}

Values in separate columns marked by the same letter $(a, b, c)$ do not differ significantly at $p=0.05$, according to HSD Tukey test.

*15 essential compounds based on stepwise discriminant analysis.

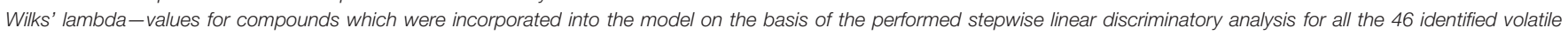
compounds. In "red" are compounds which have a highly significant effect on the differentiation of analyzed cereals. 
<smiles>CC(C=O)Cc1ccc(C(C)(C)[Al])cc1</smiles><smiles>C=C1CCCC1(C)C1(C)CC=C(C)CC1</smiles>

trichodiene<smiles>Cc1ccc(C(=O)ON(C)c2ccc(C)cc2)cc1</smiles>

p-xylene<smiles>C=CC(O)CCCCC(=O)O</smiles><smiles>CCCCCCCCCCCCCC</smiles><smiles>CCCCCCCCCCCCCCCCCCCCCCCCCCCCCC</smiles><smiles>Cc1ccc2ccccc2c1</smiles>

2-methylnaphthalene<smiles>c1ccc2c(c1)CCC2</smiles>

indane<smiles>CCCCCCCCCCC</smiles><smiles>CCCCCCC=O</smiles><smiles>CC1=CCC2C(C1)C2(C)C</smiles>

3-carene<smiles>CCc1ccccc1C</smiles>

1-ethyl-2-methylbenzene

FIGURE 3 | Structures of volatile compounds included in model of SDA.

on the first two factors F1 and F2 (Figure 8A). Triticale and bread wheat were discriminated by the F2 function, while the F1 function seems to discriminate mostly between durum wheat and triticale and bread wheat combined. Higher discriminant power was shown by: limonene, lilial, decanal, alpha-pinene, nonan-2-one, 1-decanol, benzene, nonanal, diethyl phthalate, and 3,5,5-trimethylcyclohexen-2-one. In order to find the most important variables in the model, a stepwise DA was performed. During backward stepwise analysis (Figure 8B) six compounds that contributed least to the prediction of group membership were eliminated (trichodiene, 5-butyldihydro-2(3H)-furanone, eicosane, 2-methylnaphthalene, dodecane, octanoic acid). In this case also $100 \%$ discrimination was obtained. The results of forward stepwise analysis (Figure 8C) on the other hand, allowed for a $95.83 \%$ total separation of the analyzed cereals. However, this was achieved with the inclusion of only the four following compounds: limonene, lilial, p-xylene, and indane. Since the group of compounds which contributed the most to separation was terpenes, an additional DA was carried out for this group (Figure 8D). In this case $95.83 \%$ discrimination was 


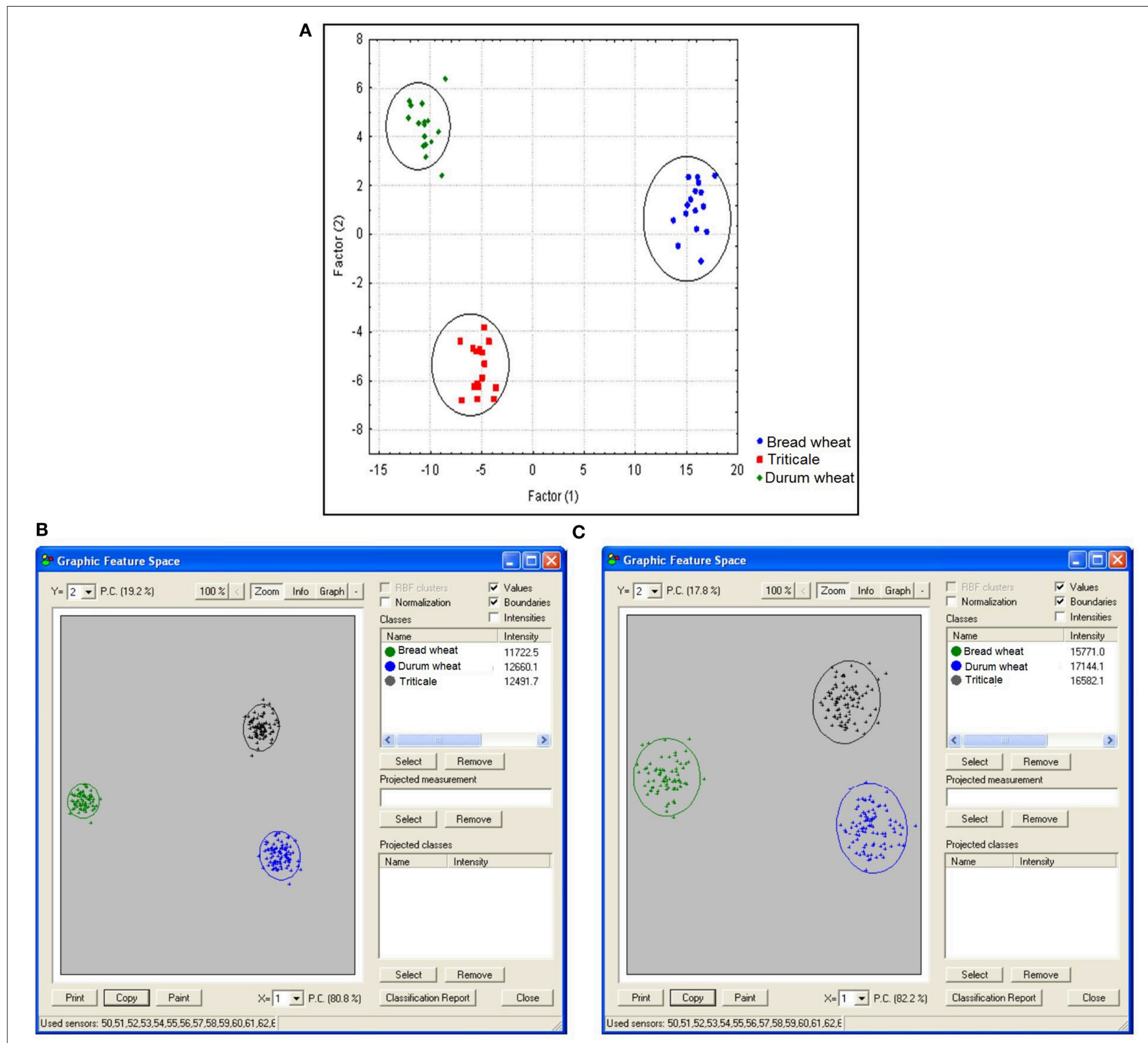

FIGURE 4 | Results of discriminatory analysis covering contents of volatile compounds identified in samples of bread wheat, durum wheat and triticale. Wilks' lambda $=0.0003778$. Function value test $F=0.8586911$, calculated for this statistic at a probability level of $P=0.00001$ (A). A map for the range of masses of 50-250 (B). A map for the range of masses of 50-150 (C).

also obtained, as only two durum wheat samples were classified as triticale.

In the final step it was decided to verify the results recorded by the application of the electronic nose. This made it possible to confirm their previously performed differentiation in terms of volatile compound profiles. For each sample the spectrum was recorded within a range of $50-250 \mathrm{~m} / \mathrm{z}$. The obtained mass spectrum was statistically analyzed using PCA. In this analysis each of the obtained $\mathrm{m} / \mathrm{z}$ values was a sensor. These sensors provided different contributions in separation of the data. Sensors which had the lowest contribution or no contribution could be eliminated from the analysis. Taking into consideration all the 200 sensors, triticale, durum wheat, and bread wheat were completely separated. The two principal components obtained in the course of this analysis explained $80.8 \%$ of differentiation (Figures 4B,C).

Thus, an attempt was made to further reduce the number of sensors in the above-mentioned range. In this case the level of contribution of individual ions in the separation of cereal into separate groups was taken into consideration. A narrowing of the PCA to only 100 ions from the $50-150 \mathrm{~m} / \mathrm{z}$ range also made it possible to completely separate all the analyzed cereals. 


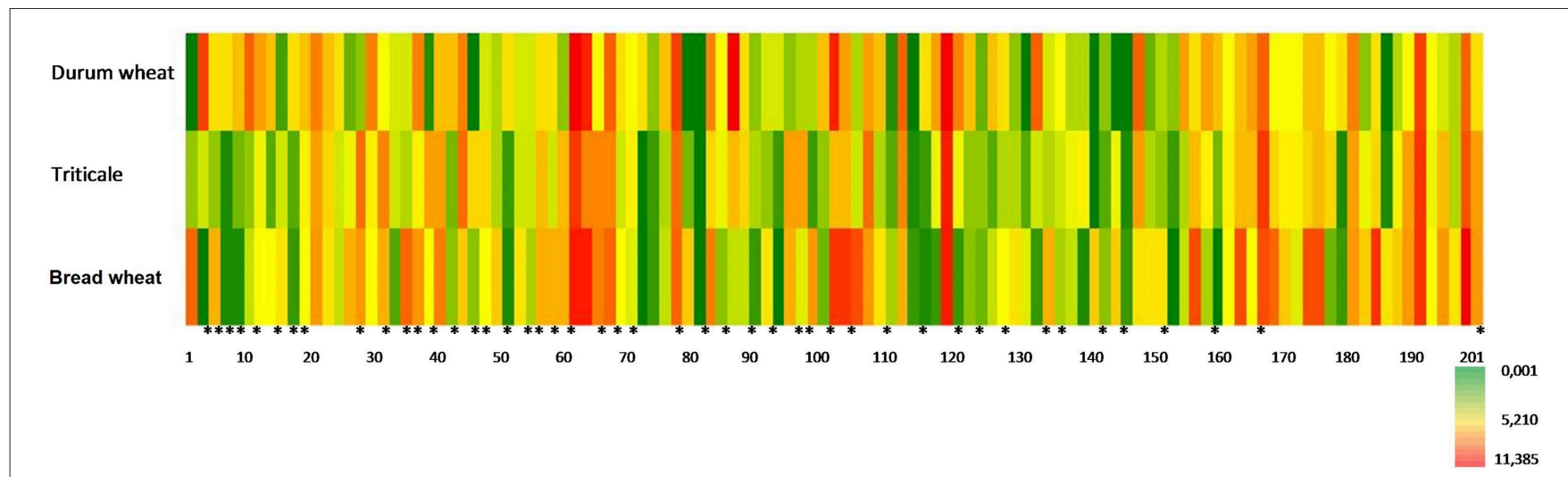

FIGURE 5 | Heatmap of all volatile compounds determined from the concentrations given as relative units (RU) ${ }^{*}$ identified volatile compounds listed in Table 3.

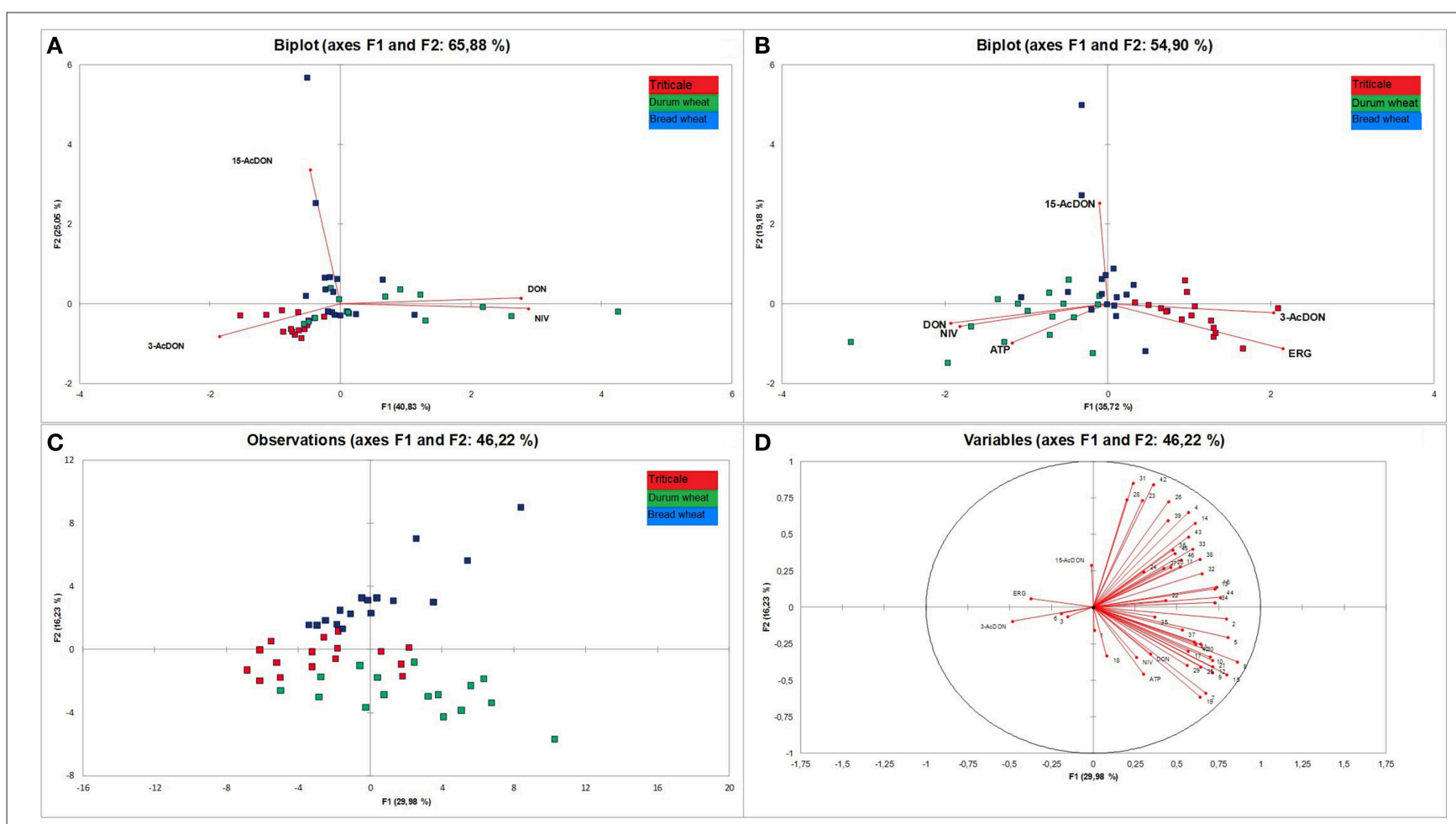

FIGURE 6 | Principal component analysis (PCA) biplots for trichothecenes of group B (A), trichothecenes, and fungal biomass indicators (ERG and ATP) (B) analyzed in 48 samples of cereal grain (triticale-red, durum wheat-green, and bread wheat-blue) and plot representing grain samples distribution (C) and correlation circle (D) of trichothecenes. ERG, ATP, and VOCs (numbers correspond to compound names as in Table 3).

\section{DISCUSSION}

In the framework of this study we analyzed three genetically similar grains: bread wheat, durum wheat, and triticale. Cereals are grown in the same ecological niche, under the same agronomic and climatic conditions. Accordingly, the environmental factors affecting the profile of fungal pathogens and the level of contamination from mycobiota as well as concentration of mycotoxins has been virtually eliminated. To date, field tests undertaken by other authors have often been subject to error as a result of the investigated crops being in different locations and under different conditions. It has been proved that weather conditions, especially rainfall during cereal flowering, have the most significant impact on the degree of pathogen infection and mycotoxin contamination level (Champeil et al., 2004). The research hypothesis of the present investigation assumed a discrimination of examinated cereals based on the profile of volatile compounds, the concentration of 

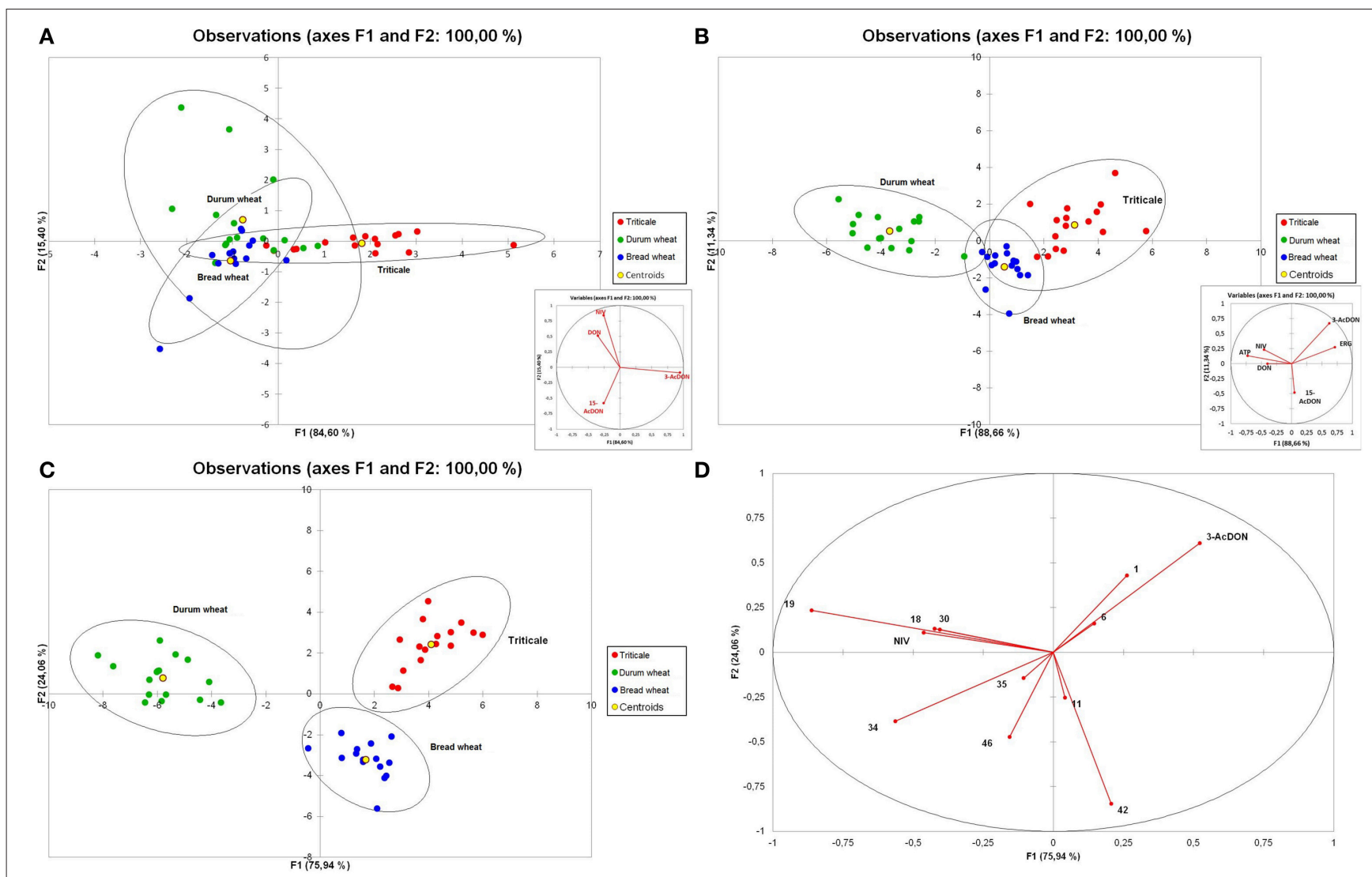

FIGURE 7 | Discriminant analysis (DA) for trichothecenes of group B-plot of observations and correlation circle for variables (A), trichothecenes and fungal biomass indicators (ERG and ATP) - plot of observations and correlation circle for variables (B) analyzed in 48 samples of cereal grain (triticale-red, durum wheat-green, and bread wheat-blue) and plot representing grain sample distribution (C) and correlation circle (D) of trichothecenes. ERG, ATP, and VOCs (numbers correspond to compound names as in Table 2).

trichothecenes group B and contamination levels measured in the mycobiota using two chemical markers for three similar cereals. Chemometric methods were applied in order to determine the relationship between the individual test parameters determining the microbiological safety of cereal grains. The analysis of grain began to determine the mycobiota contamination level of whole grains (analysis of ERG) and the surface layer (analysis of ATP). The results indicate a low level of grain contamination. Previous studies by the authors (Perkowski et al., 2007) as well as those of other investigators (Maupetit et al., 1993) have shown that the level of ERG, together with the degree of mycobiota contaminated is characteristic of a particular cereal species and the average concentration was for grain of wheat $2-4 \mathrm{mg} / \mathrm{kg}$; triticale $4-6 \mathrm{mg} / \mathrm{kg}$; barley $7-8 \mathrm{mg} / \mathrm{kg}$, rye 9-11 mg/kg oat $12-15 \mathrm{mg} / \mathrm{kg}$ (Perkowski et al., 2008b). In addition, an analysis of surface contamination was used by mean of ATP. This is a method commonly applied in the food industry, although it has not yet been widely adopted to analyse the surface contamination of cereals. Nevertheless, it was chosen due to the fact that the volatile compounds can be extracted from the surface layer of the kernel and therefore it was decided to check whether it might give results that better correspond with those for obtained volatile compounds.

Based on results determining the concentration of ATP and ERG it was found that a highly significant correlation coefficient for ERG and ATP was obtained only for a single species of grain. For all species of tested cereals no significant correlations were obtained, hence, it can be demonstrated that surface contamination of grain is related to the total infestation of the kernel, but only within individual cereal species. Pathogens are present among the native microflora of cereal grain in the field. We often see an infection of grain, and the presence of toxigenic strains of fungi of the genus Fusarium is associated with a mycotoxin produced of the group B trichothecenes at an early stage of pathogenesis. Therefore, it was decided to test a group B trichothecenes concentration in sample of cereal grains. In the climate of the Central Europe Fusarium fungi commonly dominate the ecological niche of pathogens of cereals (Logrieco and Visconti, 2004). Hence, it is necessary to analyse them for contamination by toxic metabolites which are trichothecenes. Among them, deoxynivalenol (DON) is the most common mycotoxin and is found in the highest concentrations. The above results would seem to indicate that low levels of 


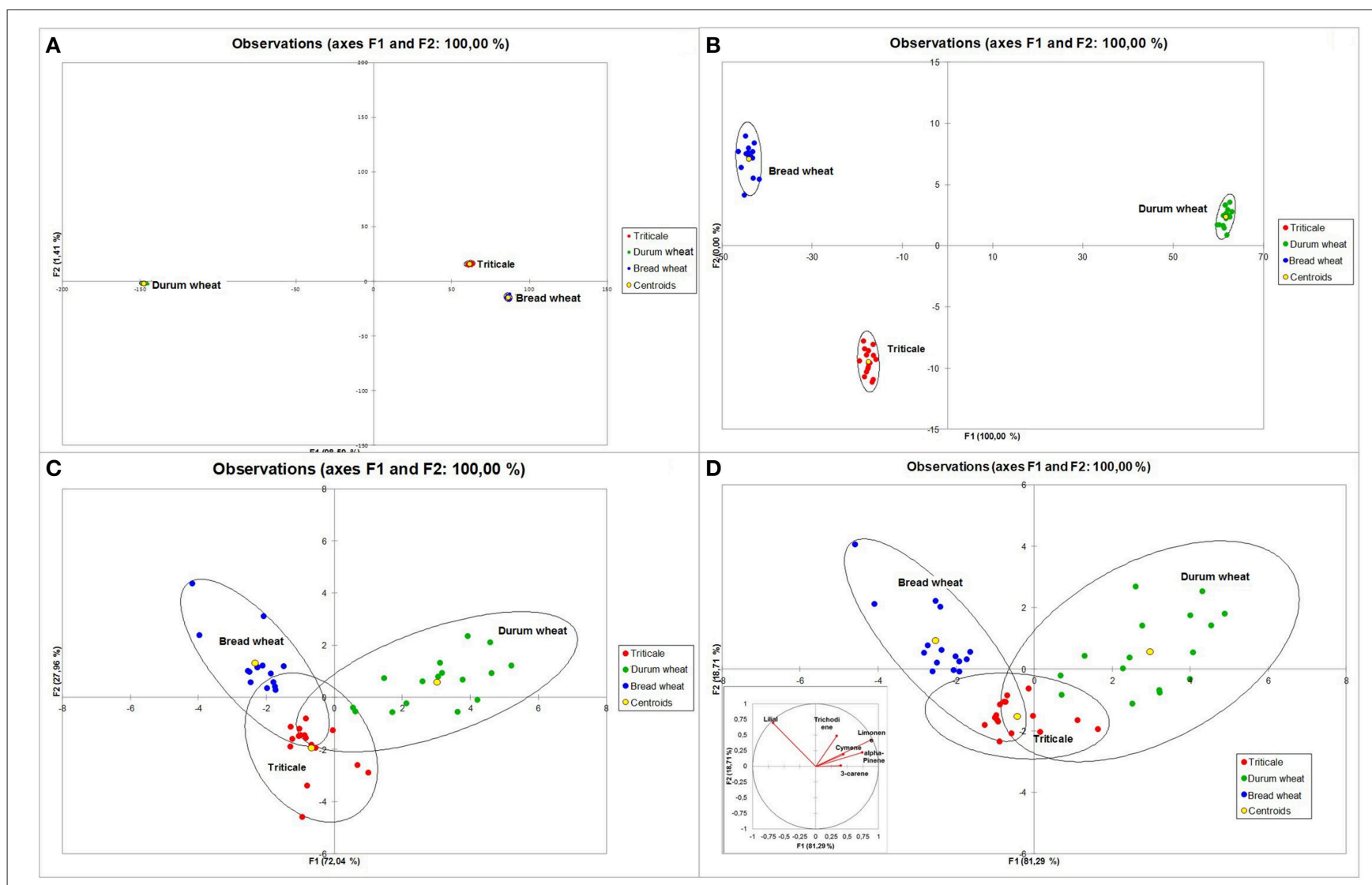

FIGURE 8 | Discriminant analysis (DA) for 46 identified VOCs-plot of observations (A), backward stepwise analysis - plot of observations (B), forward stepwise analysis - plot of observations (C) analyzed in 48 samples of cereal grain (triticale-red, durum wheat-green, and bread wheat-blue) and DA for terpenes - plot representing grain sample distribution and correlation circle (D).

contamination by trichothecenes were present in the analyzed samples of the cereal grains of the three species. In none of the tested samples were concentrations higher than the limit value indicated by the EU for the concentration of $\mathrm{DON}$ in cereals [Commission Regulation (EC) NO 1126/2007 of 28, September 2008] determined. Based on the results including levels of four mycotoxins DON, 3-AcDON, 15-AcDON, and NIV, it has been observed that in samples of triticale the results co-occurrence of DON concentrations and its acetyl derivatives differ to those of the other two wheats. Additionally, durum wheat was characterized by significantly higher concentrations of NIV. The results indicate a relationship of a quantitative profile of mycotoxins produced from cereal species. The studies of Montilla-Bascón et al. (2013) have revealed a similar relationship indicating that the same strains of toxinogenic pathogens growing on a variety of cereals may produce different amounts of mycotoxins, and even other mycotoxins. An important role is also played here by different chemotypes of particular species of microscopic fungi in the environment, as e.g.: in the case of Fusarium graminearum (Kulik, 2011). This is also related to the resistance of individual cereal species, and even to their varieties (Mesterhazy et al., 2005). During mycobiota infection of kernels compounds included in the cereal grain are broken down by microorganisms. A number of them are compounds belonging to the group of VOC's. Some of them are used in pathogenesis while others are metabolized by mycobiota, and some are metabolites of the pathogen or a native microflora. The VOC profile is therefore a mixture of compounds of different origin. One purpose of this work was to verify whether a diversity of VOCs exists even when cereals are genetically similar. The results were obtained using the two analytical methods; conventional gas chromatography coupled with a mass detector (TOF MS), and the application of an electronic nose. This combined approach has allowed the separation of the tested cereal species. It has been shown that they are characterized by a different profile of volatile compounds. It should be emphasized that as a result of the most commonly used statistical methods for this type of work (PCA and DA) metabolites were indicated to be the most differentiating tested cereal species. An important role was also played by different groups of VOCss, including terpenes. As part of our research we identified a number of compounds previously presented in the literature on the presence of VOCs in cereals. Among compounds which have discriminant power, special attention should be paid to trichodiene, observed in higher amounts in grain samples of inoculated small grain cereals (Jeleń and Wąsowicz, 1998; Demyttenaere et al., 2004) In the case 
of trichodiene, previous reports show that this compound was present in Fusarium-infected grain, since it is a volatile precursor in the trichothecene biosynthesis pathway (Jeleń et al., 1997b; Desjardins, 2006). At this point it was decided to verify the role of trichodiene, whether it may de facto differentiate individual species of cereals. To date it has been found that it differentiates cereals significantly but only those that are characterized by a higher degree of infestation with fungi from the genus Fusarium. In the analyses conducted by the authors of this study, when cereals were not significantly infested it was identified in all samples (Buśko et al., 2008).

An important observation is the lack of other sesquiterpenes in the volatile profile of the analyzed samples even though the spectrum of sesquiterpenes produced by fungi is very wide (Jelen et al., 1995; Girotti et al., 2012; Kramer and Abraham, 2012).

Apart from trichodiene, higher amounts of other volatiles were observed in the course of fungal growth. The presence of 1-hexanol, limonene, pinene, nonanal, benzene, xylenes, and styrene was frequently reported (Korpi et al., 2009).

When investigating how volatile compounds are formed, it was found that microscopic fungi produce volatile compounds on the one hand as byproducts of metabolism under conditions adverse to their development. On the other hand, it was found that they may play the role of inhibitors of metabolic changes aimed at the adaptation of the microscopic fungi to the needs of the environment they are colonizing (Wilkins et al., 2003). The spectrum of volatile compounds identified to date includes alcohols, carbonyls and hydrocarbons. The primary volatile compounds identified in grain are 3-methyl-1-butanol, 1-octen3-ol and other eight-carbon ketones and alcohols (Olsson et al., 2002; Demyttenaere et al., 2004).

Among these volatile compounds identified in samples, 1hexanol is a characteristic compound produced by Aspergillus clavatus (Jeleń and Wąsowicz, 1998) and Stachybotrys (Wilkins et al., 2003), and high concentrations were determined in semolina and oat (Sides et al., 2001; Beleggia et al., 2009). Another compound found in tested samples was 2-ethyl-1-hexanol, which was identified by Wilkins et al. (2003) as a metabolite of fungi from the genus Stachybotrys. Fungi from the genus Fusarium produce 1,2,4-trimethylbenzene (Jeleń and Wąsowicz, 1998; Olsson et al., 2000), while $\alpha$-pinene, limonene and propylbenzene are fungal metabolites (Jeleń and Wąsowicz, 1998; Beleggia et al., 2009) produced by Penicillium, F. graminearum (Jeleń et al., 1997a), and Fusarium sporotrichioides (Demyttenaere et al., 2003; Korpi et al., 2009).

Proposals for volatile compounds distinguishing individual grains have been supported by in-depth statistical analysis. However, further verification by mean of more and more often with positive results used in the laboratories of electronic nose, was performed (Buśko et al., 2014). Using 200 sensors achieved a complete separation into three groups cereals. It was assumed that reducing the number of sensors to 100 would be less effective. There have, however, been highly satisfactory results. The two methods of chemical analysis for determining the profile of VOCs supported by chemometric analysis clearly indicate that the three analyzed grains differ in their profile of volatile compounds. The use of methods including both volatile compounds, trichothecenes, ERG, and ATP allowed their exact role in the distribution of respondents cereals to be determined, together with their discriminatory strength. We hope that the results obtained will offer even a partial contribution to the study of pathogenicity in mycobiota, as well as a relevance for breeding work on obtaining varieties of these cereals resistant to environmental factors.

\section{CONCLUSION}

Examination of 16 representative genetically similar genotypes of species of cereal (bread wheat, durum wheat, and triticale), grown under identical agro-meteorological conditions leveling of the environmental impact, led to a wider knowledge of group $\mathrm{B}$ trichothecenes and volatile compounds in the grain. Further, data on the associated with them mycobiota were obtained. It was found that the method used to study the ATP level was suitable only for individual groups of cereals, no such relationship was discovered for their total population. Toxin concentration was relatively low, the profile was similar but some variation of both concentration and co-occurrence was found among crops. The VOCs profile varied and allowed for their complete separation following the GC/MS analysis, which was fully confirmed by the electronic nose. Analysing using such chemometric methods as PCA and discriminant analysis, additional informations were obtained. The chemometric analysis allowed us to determine compounds (metabolites) (mainly volatile) characterized by the greatest discriminatory force. Among the discriminating compounds were those that have been described earlier in this type of analysis by other researchers, namely: lilial, trichodiene, and p-xylene.

The designed and applied research model, based on a comprehensive analysis of all the studied traits through their thorough statistical analysis, confirmed these observations and expanded the share of group B trichothecenes and mycobiota enriched inference. The results, we believe, will give rise to further work in this area and will probably be very helpful in cereal breeding with regard to their resistance to pathogen attack and environmental factors.

\section{AUTHOR CONTRIBUTIONS}

MB, KS, HJ, JC, BT, JP designed the study, developed the methodology, collected the data, performed the analysis, and wrote the manuscript. TG designed the study, performed the field experiment, collected the data, and wrote the manuscript.

\section{ACKNOWLEDGMENTS}

This work was partially supported by the National Science Center in Poland project no. 2704/B/P01/2011/40. 


\section{REFERENCES}

Ayumi, K., and Manickavelu, A. (2015). Molecular pathogenetic study of Fusarium head blight in highly resistant, resistant and susceptible common wheat (Triticum aestivum L). Adv. Plants Agric. Res. 2:00051. doi: 10.15406/apar.2015.02.00051

Balmer, D., Flors, V., Glauser, G., and Mauch-Mani, B. (2013). Metabolomics of cereals under biotic stress: current knowledge and techniques. Front. Plant Sci. 4:82. doi: $10.3389 /$ fpls.2013.00082

Beleggia, R., Platani, C., Spano, G., Monteleone, M., and Cattivelli, L. (2009). Metabolic profiling and analysis of volatile composition of durum wheat semolina and pasta. Cereal Sci. 49, 301-309. doi: 10.1016/j.jcs.2008.12.002

Borjesson, T., Eklov, T., Jonsson, A., Sundgren, H., and Schnurer, J. (1996). Electronic nose for odor classification of grains. Cereal Chem. 73, 457-461.

Borjesson, T., Stollman, U., and Schnurer, J. (1992). Volatile metabolites produced by 6 fungal species compared with other indicators of fungal growth on cereal-grains. Appl. Environ. Microbiol. 58, 2599-2605.

Boutigny, A. L., Richard-Forget, F., and Barreau, C. (2008). Natural mechanisms for cereal resistance to the accumulation of Fusarium trichothecenes. Eur. J. Plant Pathol. 121, 411-423. doi: 10.1007/s10658-007-9266-x

Buśko, M., Jeleń, H., Góral, T., Chmielewski, J., Stuper, K., Szwajkowska-Michalek, L., et al. (2010). Volatile metabolites in various cereal grains. Food Addit. Contam. Part A Chem. Anal. Control Expo. Risk Assess. 27, 1574-1581. doi: 10.1080/19440049.2010.506600

Buśko, M., Kulik, T., Ostrowska, A., Góral, T., and Perkowski, J. (2014). Quantitative volatile compound profiles in fungal cultures of three different Fusarium graminearum chemotypes. FEMS Microbiol. Lett. 359, 85-93. doi: 10.1111/1574-6968.12569

Buśko, M., Perkowski, J., Wiwart, M., Goral, T., Suchowilska, E., Stuper, K., et al. (2008). Distribution of fungal biomass in spike of naturally contaminated and inoculated with Fusarium culmorum. Cereal Res. Commun. 36, 477-479. doi: 10.1556/CRC.36.2008.Suppl.B.38

Champeil, A., Dore, T., and Fourbet, J. F. (2004). Fusarium head blight: epidemiological origin of the effects of cultural practices on head blight attacks and the production of mycotoxins by Fusarium in wheat grains. Plant Sci. 166, 1389-1415. doi: 10.1016/j.plantsci.2004.02.004

Chantret, N., Salse, J., Sabot, F., Rahman, S., Bellec, A., Laubin, B., et al. (2005). Molecular basis of evolutionary events that shaped the hardness locus in diploid and polyploid wheat species (Triticum and aegilops). Plant Cell 17, 1033-1045. doi: $10.1105 /$ tpc. 104.029181

Condain, L. (1999). Cereal gnains: humanity's double-edged swond. Evolutionary aspects of nutrition and health. World Rev. Nutr. Diet. 84, 15-73.

Demyttenaere, J., Moriña, R., De Kimpe, N., and Sandra, P. (2004). Use of headspace solid-phase microextraction and headspace sorptive extraction for the detection of the volatile metabolites produced by toxigenic Fusarium species. J. Chromatogr. A 1027, 147-154. doi: 10.1016/j.chroma.2003. 08.105

Demyttenaere, J., Moriña, R., and Sandra, P. (2003). Monitoring and fast detection of mycotoxin-producing fungi based on headspace solid-phase microextraction and headspace sorptive extraction of the volatile metabolites. J. Chromatogr. A 985, 127-135. doi: 10.1016/S0021-9673(02)01417-6

Desjardins, A. E. (2006). Fusarium Mycotoxins: Chemistry, Genetics, and Biology. St. Paul, MN: American Phytopathological Society Press.

Eudes, F. (2015). Triticale. Cham: Springer International Publishing.

Girotti, J., Malbran, I., Lori, G., and Juarez, M. (2012). Early detection of toxigenic Fusarium graminearum in wheat. World Mycotoxin J. 5, 143-152. doi: 10.3920/WMJ2011.1348

Hestbjerg, H., Nielsen, K. F., Thrane, U., and Elmholt, S. (2002). Production of trichothecenes and other secondary metabolites by Fusarium culmorum and Fusarium equiseti on common laboratory media and a soil organic matter agar: an ecological interpretation. J. Agric. Food Chem. 50, 7593-7599. doi: $10.1021 /$ jf020432o

Jeleń, H., Kaminski, E., and Wąsowicz, E. (1997a). Volatile sesquiterpenes as an indicator for toxigenic Fusaria contamination. Food Sci. Technol. 1, 49-60.

Jeleń, H., Latus-Zietkiewicz, D., Wasowicz, E., and Kaminski, E. (1997b). Trichodiene as a volatile marker for trichothecenes biosynthesis. J. Microbiol. Methods 31, 45-49. doi: 10.1016/S0167-7012(97)00088-2
Jeleń, H., Mirocha, C. J., Wasowicz, E., and Kamiński, E. (1995). Production of volatile sesquiterpenes by Fusarium sambucinum strains with different abilities to synthesize trichothecenes. Appl. Environ. Microbiol. 61, 3815-3820.

Jeleń, H., and Wąsowicz, E. (1998). Volatile fungal metabolites and their relation to the spoilage of agricultural commodities. Food Sci. Technol. 14, 391-426. doi: $10.1080 / 87559129809541170$

Kimura, M., Tokai, T., O'donnell, K., Ward, T. J., Fujimura, M., Hamamoto, H., et al. (2003). The trichothecene biosynthesis gene cluster of Fusarium graminearum F15 contains a limited number of essential pathway genes and expressed non-essential genes. FEBS Lett. 539, 105-110. doi: 10.1016/S00145793(03)00208-4

Korpi, A., Jarnberg, J., and Pasanen, A. L. (2009). Microbial volatile organic compounds. Crit. Rev. Toxicol. 39, 139-193. doi: 10.1080/10408440802291497

Kramer, R., and Abraham, W.-R. (2012). Volatile sesquiterpenes from fungi: what are they good for? Phytochem. Rev. 11, 15-37. doi: 10.1007/s11101-011-9216-2

Kulik, T. (2011). Development of TaqMan Assays for 3ADON, 15ADON and NIV Fusarium genotypes based on Tri12 gene. Cereal Res. Commun. 39, 200-214. doi: 10.1556/CRC.39.2011.2.4

Lee, T., Han, Y. K., Kim, K. H., Yun, S. H., and Lee, Y. W. (2002). Tri13 and Tri7 determine deoxynivalenol- and nivalenol-producing chemotypes of Gibberella zeae. Appl. Environ. Microbiol. 68, 2148-2154. doi: 10.1128/AEM.68.5.21482154.2002

Logrieco, A., and Visconti, A. (2004). Overview of Toxigenic Fungi and Mycotoxins in Europe. Dordrecht: Kluwer Academic Publishers.

Magan, N., and Evans, P. (2000). Volatiles as an indicator of fungal activity and differentiation between species, and the potential use of electronic nose technology for early detection of grain spoilage. J. Stored Prod. Res. 36, 319-340. doi: 10.1016/S0022-474X(99)00057-0

Maupetit, P., Gatel, F., Cahagnier, B., Botorel, G., Charlier, M., Collet, B., et al. (1993). "Quantitative estimation of fungal infestation of feedstuffs by determining ergosterol content," in 44th Annual Meeting of the EAAP (Aarhus: Commission of Animal Nutrition).

Mellon, J. E., Dowd, M. K., and Cotty, P. J. (2002). Time course study of substrate utilization by Aspergillus flavus in medium simulating corn (Zea mays) kernels. J. Agric. Food Chem. 50, 648-652. doi: 10.1021/jf011048e

Mellon, J. E., Dowd, M. K., and Cotty, P. J. (2005). Substrate utilization by Aspergiilus flavus in inoculated whole corn kernels and isolated tissues. J. Agric. Food Chem. 53, 2351-2357. doi: 10.1021/jf040276g

Mesterhazy, A., Bartok, T., Kaszonyi, G., Varga, M., Toth, B., and Varga, J. (2005). Common resistance to different Fusarium spp. causing Fusarium head blight in wheat. Eur. J. Plant Pathol. 112, 267-281. doi: 10.1007/s10658-005-2853-9

Mitterbauer, R., Poppenberger, B., Raditschnig, A., Lucyshyn, D., Lemmens, M., Glössl, J., et al. (2004). Toxin-dependent utilization of engineered ribosomal protein L3 limits trichothecene resistance in transgenic plants. Plant Biotechnol. J. 2, 329-340. doi: 10.1111/j.1467-7652.2004.00075.x

Montilla-Bascón, G., Sánchez-Martín, J., Rispail, N., Rubiales, D., Mur, L. A. J., Langdon, T., et al. (2013). Genetic diversity, pathogens and population structure toamong cereals cultivars and landraces. Plant Mol. Biol. Rep. 31, 1305-1314. doi: 10.1007/s11105-013-0598-8

Mugrabi de Kuppler, A. L., Steiner, U., Sulyok, M., Krska, R., and Oerke, E. C. (2011). Genotyping and phenotyping of Fusarium graminearum isolates from Germany related to their mycotoxin biosynthesis. Int. J. Food Microbiol. 151, 78-86. doi: 10.1016/j.ijfoodmicro.2011.08.006

Müller, H. M., and Schwadorf, K. (1999). Ergosterol and fungal count in cereal by-products. J. Anim. Physiol. Anim. Nutr. 64, 215-219. doi: 10.1111/j.14390396.1990.tb00224.x

Olsson, J., Börjesson, T., Lundstedt, T., and Schnürer, J. (2000). Volatiles for mycological quality grading of barley grains: determinations using gas chromatography-mass spectrometry and electronic nose. Int. J. Food Microbiol. 59, 167-178. doi: 10.1016/S0168-1605(00)00355-X

Olsson, J., Börjesson, T., Lundstedt, T., and Schnürer, J. (2002). Detection and quantification of ochratoxin A and deoxynivalenol in barley grains by GC-MS and electronic nose. Int. J. Food Microbiol. 72, 203-214. doi: 10.1016/S01681605(01)00685-7

Panagiotou, G., Christakopoulos, P., and Olsson, L. (2005). The influence of different cultivation conditions on the metabolome of Fusarium oxysporum. J. Biotechnol. 118, 304-315. doi: 10.1016/j.jbiotec.2005.05.004 
Perkowski, J., Busko, M., Chmielewski, J., Góral, T., and Tyrakowska, B. (2008a). Content of trichodiene and analysis of fungal volatiles (electronic nose) in wheat and triticale grain naturally infected and inoculated with Fusarium culmorum. Int. J. Food Microbiol. 126, 127-134. doi: 10.1016/j.ijfoodmicro.2008.05.028

Perkowski, J., Buśko, M., Stuper, K., Kostecki, M., Matysiak, A., and Szwajkowska-Michałek, L. (2008b). Concentration of ergosterol in smallgrained naturally contaminated and inoculated cereals. Biologia 63, 542-547. doi: 10.2478/s11756-008-0083-2

Perkowski, J., Kiecana, I., and Kaczmarek, Z. (2003). Natural occurrence and distribution of Fusarium toxins in contaminated barley cultivars. Eur. J. Plant Pathol. 109, 331-339. doi: 10.1023/A:1023547210060

Perkowski, J., Stuper, K., Buśko, M., Góral, T., Kaczmarek, A., and Jeleń, H. (2012). Differences in metabolomic profiles of the naturally contaminated grain of barley, oats and rye. J. Cereal Sci. 56, 544-551. doi: 10.1016/j.jcs.2012. 07.012

Perkowski, J., Wiwart, M., Buśko, M., Laskowska, M., Berthiller, F., Kandler, W., et al. (2007). Fusarium toxins and total fungal biomass indicators in naturally contaminated wheat samples from north-eastern Poland in 2003. Food Addit. Contam. 24, 1292-1298. doi: 10.1080/02652030701 416566

Proctor, R. H., Desjardins, A. E., McCormick, S. P., Plattner, R. D., Alexander, N. J., and Brown, D. W. (2002). Genetic analysis of the role of trichothecene and fumonisin mycotoxins in the virulence of Fusarium. Eur. J. Plant Pathol. 108, 691-698. doi: 10.1023/A:1020637832371

Sahgal, N., Needham, R., Cabañes, F. J., and Magan, N. (2007). Potential for detection and discrimination between mycotoxigenic and nontoxigenic spoilage moulds using volatile production patterns: a review. Food Addit. Contam. 24, 1161-1168. doi: 10.1080/02652030701 519096
Schnürer, J., Olsson, J., and Börjesson, T. (1999). Fungal volatiles as indicators of food and feeds spoilage. Fungal Genet. Biol. 27, 209-217. doi: 10.1006/fgbi.1999.1139

Schroeder, H. W., and Christensen, J. J. (1963). Factors affecting resistance of wheat to scab by Gibberella zeae. Phytopathology 53, 831-838.

Sides, A., Robards, K., Helliwell, S., and An, M. (2001). Changes in the volatile profile of oats induced by processing. J. Agric. Food Chem. 49, 2125-2130. doi: 10.1021/jf0010127

Stępień, Ł., and Chełkowski, J. (2010). Fusarium head blight of wheat: pathogenic species and their mycotoxins. World Mycotoxin J. 3, 107-119. doi: 10.3920/WMJ2009.1193

Suberkropp, K., Gessner, M. O., and Chauvet, E. (1993). Comparison of ATP and ergosterol as indicators of fungal biomass associated with decomposing leaves in streams. Appl. Environ. Microbiol. 59, 3367-3372.

Wilkins, K., Nielsen, K. F., and Din, S. U. (2003). Patterns of volatile metabolites and nonvolatile trichothecenes - produced by isolates of Stachybotrys, Fusarium, Trichoderma, Trichothecium and Memnoniella. Environ. Sci. Pollut. R. 10, 162-166. doi: 10.1065/espr2002.05.118

Conflict of Interest Statement: The authors declare that the research was conducted in the absence of any commercial or financial relationships that could be construed as a potential conflict of interest.

Copyright (C) 2016 Buśko, Stuper, Jeleń, Góral, Chmielewski, Tyrakowska and Perkowski. This is an open-access article distributed under the terms of the Creative Commons Attribution License (CC BY). The use, distribution or reproduction in other forums is permitted, provided the original author(s) or licensor are credited and that the original publication in this journal is cited, in accordance with accepted academic practice. No use, distribution or reproduction is permitted which does not comply with these terms. 